\title{
Does Access to Rapid Prototyping Enhance Student Vision-ization?
}

\author{
Thomas E. Doyle \\ McMaster University \\ doylet@mcmaster.ca
}

\begin{abstract}
At its core, engineering technical design is the process of taking a concept to creation. In order to achieve successful technical design a student must combine their idea or vision of a solution (function) with a visualization of the part/assembly (form) -- referred to henceforth as vision-ization. Teaching technical design to a large first-year class of engineering students presents a number of challenges, but perhaps the most significant is the rapid change of the tools used in engineering technical design. To be clear, the tools themselves are not the challenge, as the students generally have no trouble mastering the tools. The challenge lies in the teaching and ultimately the learning objectives; at a University level the fundamental question is what pedagogical benefit does a tool provide without the knowledge to apply it? As the tools have advanced, the students (and the instructors) find themselves further from the design process resulting in course topics perceived as disconnected or without relevance. In 2006 McMaster University's first-year engineering program departed from the traditional method of teaching engineering design, which was heavily focussed on form, to establish design function as the primary objective of the course. With a yearly enrolment near 1000 students, the scalability of teaching and evaluating design function was implemented using a customized simulation and visualization tool. The simulation was extended to the logical use of rapid prototyping machines (3D-printers) for physical creation and testing. This paper will present the author's initial analysis of the link between pure visualization, applied visualization, and success in functional design via rapid prototyping.
\end{abstract}

